\title{
Measurement of plasma volume in neonates
}

\author{
M Y Anthony, S R Goodall, M Papouli, M I Levene
}

\begin{abstract}
There is no reliable and safe method for measuring plasma volume in ill newborn infants. We describe an adaptation of the dye dilution technique using indocyanine green as the plasma label, which can be used in the sickest and smallest of infants with the minimum of disturbance. To avoid the need to take large volumes of blood from the infant, samples were diluted 1:1 with distilled water and pooled adult sera was used to construct the dye dilution standard curves. Eighteen preterm and fullterm infants were studied on 30 occasions. The measured plasma volume ranged between 21.4 and $106 \mathrm{ml} / \mathrm{kg}$. Paired measurements were performed within 30-90 minutes of each other in seven infants. In five infants estimations of plasma volume were made shortly before and $\mathbf{3 0}$ minutes after the infusion of a known quantity of plasma. In eight out of 12 infants who had two measurements made there was close agreement between the second measured volume and the first measured volume, taking into account how much plasma had been given to or taken from the infant between the two measurements. The error ranged from 0.2 to $5.2 \mathrm{ml}$ and the plasma recovery error ranged from $-2.9 \%$ to $+4 \cdot 7 \%$. In the remaining four infants the errors ranged from 2.1 to $9.5 \mathrm{ml}$ and $-14 \cdot 2 \%$ to $+8 \cdot 8 \%$. Errors in the measurement of plasma volume may arise as the result of sampling too early before full mixing of the dye has occurred, and there is a potential error in the measurement due to the distribution of albumin in the extracellular space in sick infants resulting in an overestimation of the plasma volume. Proposals for reducing sources of errors are discussed.
\end{abstract}

The sick newborn infant is particularly prone to compartmental fluid shifts resulting in fluid and electrolyte imbalances. Fluid balance is clinically assessed in the neonate by measurement of electrolytes and osmolalities in the serum and urine, as well as urinary output and changes in body weight. In some infants who develop renal impairment, cardiac failure, or severe oedema the fluid and electrolyte management may become extremely difficult. In adults, or sometimes in larger infants, invasive central venous pressure monitoring may be used as a guide to intravascular filling. This is rarely technically feasible in the preterm neonate and there are no normal reference values available for this measurement.

An alternative approach to assessment of circulating plasma volumes is the injection of plasma dyes and the measurement of resulting dilutions. ${ }^{1-3}$ In neonates, radiolabelled albumin and Evans' blue have been used for this purpose. ${ }^{4-9}$ Evans' blue is no longer commercially available and the use of radiolabelled albumin in neonates is restricted by ethical considerations to exceptional circumstances and certainly may not be used repeatedly. An alternative dye, indocyanine green (ICG) has been used in adults, in children with cardiac conditions, and in veterinary practice ${ }^{10-13}$ and has been shown to be safe. It has been used in adults specifically to measure plasma volume and the method validated against radiolabelled albumin measurements. ${ }^{10}$

The purpose of this pilot study was to adapt the ICG dye dilution method of measuring plasma volume to small and sick neonates, in whom the greatest constraint is the volume of blood which may be taken for measuring the dye's dilution in the circulation.

We are specifically concerned with the measurement of plasma volume. Alternative methods may be employed for directly measuring red cell mass using a red cell label. An approximation to the red cell mass and thus total blood volume may be made from the plasma volume measurement and the corrected total body packed cell volume. ${ }^{16}$

\section{Methods}

THEORY

The principle of measuring circulating volumes by dissolving a known quantity of dye and measuring the resulting concentration is essentially simple, but there are a number of theoretical considerations ${ }^{1}$ and in the preterm subject a number of practical considerations which have to be overcome.

If a known quantity of solute, $Q$, is dissolved in volume $\mathrm{V}$, the resulting concentration is $\mathrm{C}$, such that $\mathrm{C}=\mathrm{Q} / \mathrm{V}$ and $\mathrm{V}=\mathrm{Q} / \mathrm{C}$. However, the solute or dye must mix and be evenly distributed throughout the entire volume. In the human circulation, different organ systems will have different circulation times and therefore there will be a phase when the dye concentration measured in the central circulation will be fluctuating before the concentration comes to an equilibrium throughout the entire body. The time taken for the dye to reach this equilibrium is known as the mixing time. An absolute criterion for complete mixing is difficult to establish, but a realistic point for a temporary dye, such as ICG, is taken when there is a constant rate of decline in the dye concentration 
in the central circulation. ${ }^{1}$ The mixing time would theoretically be influenced by the dye indicator used and the state of the patient (for example, cardiac output, blood volume, and splenomegaly). In adult humans the mixing time for ICG has been shown to be in the order of 60 seconds. ${ }^{10}$

Once the dye has been injected it will be lost from the circulation, either to the extravascular compartment or by excretion. If the concentration of the dye could be measured constantly from the moment it was injected, and plotted against time, there would be a periodic fluctuation in the dye concentration for the duration of the mixing time, superimposed upon an exponential decline in concentration due to loss of dye from the circulation (fig 1).

The concentration value that must be known for the equation $V=Q / C$ is the concentration of the dye in equilibrium throughout the entire body system before any of the dye is lost. This may be found by plotting on a log scale the exponential decay curve of the dye, after the mixing time is complete. This will produce a straight line, which on reverse extrapolation to time zero will provide the log value of the required concentration. Theoretically, at this time no dye will have been lost and it will be evenly distributed throughout the body.

Radiolabelled albumin markers have generally been considered the best method of measuring plasma volume, partly because albumin is considered less likely to leak from the circulation. ICG is strongly bound to albumin and thus is a good marker of plasma volume. ${ }^{14} 15$ In a sick neonate there is likely to be considerable capillary leakage, but extrapolation of the decay curve to time zero makes allowances for this loss. The steeper the decay curve the more rapidly the dye is being lost. This method for calculating a value for $\mathrm{C}$ and thus $\mathrm{V}$ has been shown in adults to correlate well with the radiolabelled albumin method. ${ }^{10}$

In those disease states where transcapillary leakage is marked it has been postulated that plasma volume measurements made using albumin markers will overestimate the result because the albumin in these very leaky patients

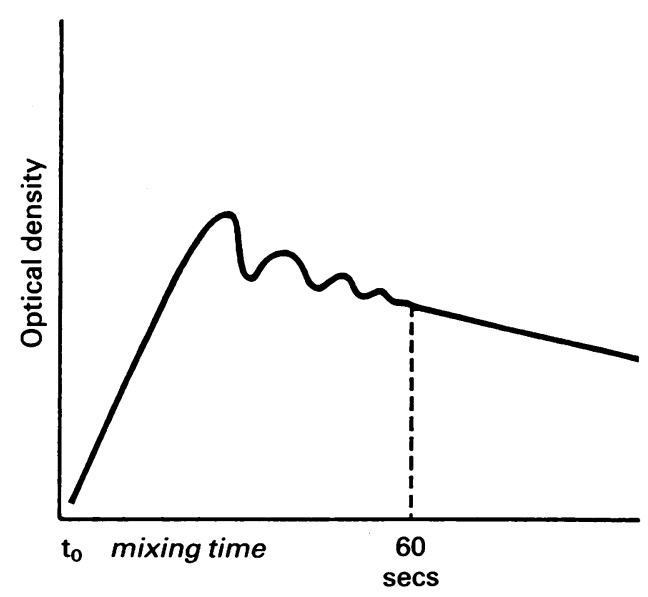

Figure 1 Idealised decay curve for ICG. is distributed throughout the extravascular as well as intravascular compartment. ${ }^{14}$ Extrapolation back to time zero will make allowances for the leak of albumin out of the circulation but not for the theoretical leak back into the circulation of albumin from the extravascular space. The size of this shifting albumin pool or its speed of circulation is not known. Various studies of plasma volume in adults in whom capillary leakage is expected to be pronounced, such as after cardiac surgery, have been undertaken either comparing albumin measurements of plasma volume and derived values from red cell volumes and packed cell volumes, or albumin measurements and values measured using larger molecular plasma labels such as dextran. The errors recorded in the overestimation of plasma volume using albumin vary from $1 \cdot 2 \%$ to $10 \% .{ }^{14}$

Estimates of total blood volume and red cell volume may be derived from the measured plasma volume and a corrected mean body packed cell volume. Conversely plasma volume (PV) and blood volume may be estimated from techniques for measuring red cell volume and a corrected mean body packed cell volume. A measured pack cell volume is not an accurate measure throughout the entire body. For neonates it has been shown that a correction factor of 0.87 should be applied such that mean body packed cell volume $(\mathrm{mPCV})=0.87 \times$ measured PCV. ${ }^{16}$ The cell volume (CV) in $\mathrm{ml}$ can be calculated approximately as: $\mathrm{CV}=\mathrm{PV} \times \mathrm{m}$ $\mathrm{PCV} / \mathrm{l}-\mathrm{mPCV}$ and the blood volume (BV) in $\mathrm{ml}=\mathrm{CV}+\mathrm{PV}$.

\section{MATERIALS}

ICG was obtained in 25 or $50 \mathrm{mg}$ vials from Becton-Dickenson Microbiology Systems. It is a non-toxic, non-permanent dye which is rapidly removed from the circulation by the liver (half life $<10 \mathrm{~min}$ ), which enables frequent repeated measurements in an individual. It is water soluble with a spectral absorption at $800-810$ $\mathrm{nm}$ in plasma. Haemoglobin and oxyhaemoglobin do not absorb at these wavelengths, therefore the oxygen saturation does not affect the readings, nor do bilirubin or drugs.

ICG does not stain the skin or mucous membranes. It contains $0.5 \%$ sodium iodide and is therefore contraindicated in patients with a history of allergy to iodides; radioactive iodine uptake studies should not be performed for at least a week after the use of ICG. Excretion is impaired by liver dysfunction and it is rapidly bound to albumin. It is contraindicated in jaundice severe enough to require phototherapy. Light fades the dye so all samples must be kept in light proof containers. The aqueous solution is only stable for 10 hours. ${ }^{10} 15$

Standard curve preparations were made from $400 \mathrm{ml}$ of pooled blood donations from two healthy adults. A Pye Unicam SPA-100 dual beam scanning spectrophotometer was used to plot the peak absorption before and after the dilution of samples with water. Subsequent study samples were analysed in a Cecil CE 292 spectrophotometer which requires smaller sample volumes. 


\section{PATIENTS}

Any infant receiving intensive care requiring both an intravenous and an arterial line for clinical purposes and who was not receiving phototherapy was considered suitable for study. Lipaemic serum interferes with the spectral assay and therefore infants receiving Intralipid (Kabi) were excluded. The study was approved by the hospital ethics committee and informed parental consent was obtained.

A total of 18 infants were studied on 30 occasions. Six of the infants were studied once (group 1), five were studied immediately before and 30 minutes after the infusion of a known quantity of plasma (group 2), and a further seven were studied twice with no infusion of plasma (group 3) 30 to 90 minutes apart. Two of the infants from group 1 were studied for clinical reasons to assess their state of intravascular hydration.

\section{TECHNIQUE}

\section{Measurement of plasma volume}

The ICG powder was reconstituted in distilled water according to the manufacturer's recommendations. Solutions of $0 \cdot 25,0 \cdot 50$, or $1.0 \mathrm{mg} / \mathrm{l}$ were prepared such that the volume required to administer $0.2 \mathrm{mg} / \mathrm{kg}$ to the baby was between $0.4 \mathrm{ml}$ and $1.0 \mathrm{ml}$. A dose of $0.2 \mathrm{mg} / \mathrm{kg}$ ICG brings the expected concentrations from $t_{0}$ to $\mathrm{t}_{6} \mathrm{~min}_{\text {min }}$ onto the linear part of the standard curve. Before ICG was given, $0.8 \mathrm{ml}$ of blood was withdrawn from the indwelling arterial line: $0.2 \mathrm{ml}$ was used to measure the packed cell volume, the remainder allowed to clot in the dark in a small plain tube. At $t_{0}$ the bolus of ICG was injected intravenously and flushed through with water. Three further samples of $0.6 \mathrm{ml}$ were taken into small plain tubes at timed intervals between 1 and 6 minutes after injection and allowed to clot in the dark. The exact time each sample was withdrawn and the total volume of blood taken was recorded.

A portion of the reconstituted ICG was retained for weighing and the preparation of the standard solutions. The syringe used to inject the ICG was weighed before and after the ICG was given to calculate the quantity of ICG given.

Serum was removed from the clotted blood sample, diluted 1:1 with distilled water and the absorbance at $805 \mathrm{~nm}$ recorded. ICG concentration was deduced from the water diluted standard curve, and the plasma volume calculated from the equations shown below.

\section{ICG standard curve}

A standard curve was produced for each study using sera from the adult pool and the same reconstituted ICG as used in the subjects to eliminate any error in the reconstitution of the ICG powder with distilled water. The reconstituted ICG was further diluted with serum to give ICG standard values of $1 \cdot 25,2 \cdot 50,5 \cdot 00$, and $10 \mathrm{mg} / 1$. A serum only sample was kept as the blank. Portions of all the standard samples were further diluted 1:1 with distilled water. The optical density measured by the spectro- photometer for each standard sample at $805 \mathrm{~nm}$ was recorded and plotted graphically

\section{ICG absorption maximum}

Standard solutions and sera taken from subjects after administration of ICG were scanned spectrophotometrically from $750 \mathrm{~nm}$ to $850 \mathrm{~nm}$. The blank adult sera (standards) and the infant's serum before ICG were used to provide the zero baseline. All samples were rescanned after a 1:1 dilution with distilled water.

\section{CALCULATIONS}

\section{Dose of ICG given}

If $\mathrm{W}$, the weight (in $\mathrm{mg}$ ) of the ICG solution administered; $\mathrm{Z}$, the weight (in $\mathrm{mg}$ ) of $1.00 \mathrm{ml}$ IGC; and $A$, the concentration (in $\mathrm{mg} / \mathrm{ml}$ ) of ICG in solution, are all known, then $D$, the dose (in mg) of ICG to administer can be calculated:

$$
\mathrm{D}=(\mathbf{W} \times \mathbf{A}) / \mathbf{Z}
$$

\section{Plasma volume}

$\log _{e}$ serum ICG concentration is plotted against time. The linear regression line is reverse extrapolated to provide the effective concentration of ICG at time $t_{0}\left(I_{C G}\right)$. Thus PV, plasma volume (in $\mathrm{ml}$ ) can be calculated:

$$
\mathrm{PV}=\mathrm{D} / \mathrm{ICG}_{0}
$$

\section{Plasma recovery}

In order to assess the method's reliability and reproducibility we performed paired measurements in a number of infants (groups 2 and 3) In group 2, measurements were made immediately before $\left(P V_{1}\right)$, and 30 minutes after $\left(P V_{2}\right)$ a known quantity of plasma had been infused over a 60 minute period. In group 3, two measurements of plasma volume $\left(P V_{1}\right.$ and $\left.P V_{2}\right)$ were made 30-90 minutes apart to see how closely the second volume measurement came to the expected value. Plasma recover (PR) (in \%) was calculated as:

$$
\mathrm{PR}=\mathrm{PV}_{2} /\left(\mathrm{PV}_{1} \pm \text { infusion or sample }\right) \times 100 \text {. }
$$

\section{Results}

The maximum spectral absorption of both infant and adult serum, either neat or diluted 1:1 with water, was $803-805 \mathrm{~nm}$. Figure 2 shows the decay curves for ICG for one of the infants before and after plasma has been given. The plasma half life of ICG varied from $2 \cdot 37$ to 12.07 minutes, with the longer times corresponding to the larger volumes.

The infants gestational ages ranged from 26 to 41 weeks (median 30 weeks) and their birth weights from $780-3900 \mathrm{~g}$ (median $1210 \mathrm{~g}$ ). The range of plasma volumes was 21.4 to 106.3 $\mathrm{ml} / \mathrm{kg}$ (median $40.9 \mathrm{mg} / \mathrm{kg}$ ), see table.

The infant at the lowest extreme of plasma volume was a term, postoperative infant who was very oedematous but had evidence of vascular underfilling with a low urine output and, in this case, a central venous pressure line was in situ recording $2 \mathrm{~mm} \mathrm{Hg}$. The infant at 
Patient details and results

\begin{tabular}{|c|c|c|c|c|c|c|c|c|c|}
\hline $\begin{array}{l}\text { Patient } \\
\text { No }\end{array}$ & $\begin{array}{l}\text { Birth } \\
\text { weight } \\
\text { (g) }\end{array}$ & $\begin{array}{l}\text { Gestational } \\
\text { age (weeks)/postnatal } \\
\text { age (days) }\end{array}$ & $\begin{array}{l}P V_{1} \\
(m l)\end{array}$ & $\begin{array}{l}P V / k g \\
(\mathrm{ml} / \mathrm{kg})\end{array}$ & $\begin{array}{l}P V_{2} \\
(m l)\end{array}$ & $\begin{array}{l}\text { Net } \\
\text { volume } \\
\text { given } \\
(m l)\end{array}$ & $\begin{array}{l}\text { Error } \\
(m l)\end{array}$ & $\begin{array}{l}\text { Plasma } \\
\text { recovery } \\
(\%)\end{array}$ & $\begin{array}{l}\text { Error } \\
(\%)\end{array}$ \\
\hline \multicolumn{10}{|c|}{ Group 1: Single volume measurement } \\
\hline 1 & 1780 & $34 / 5$ & $68 \cdot 8$ & $38 \cdot 7$ & & & & & \\
\hline 2 & 1960 & $31 / 3$ & $99 \cdot 4$ & $50 \cdot 7$ & & & & & \\
\hline 3 & 780 & $26 / 3$ & $37 \cdot 5$ & $48 \cdot 1$ & & & & & \\
\hline 4 & 3900 & $41 / 1$ & $83 \cdot 4$ & $21 \cdot 4$ & & & & & \\
\hline 5 & 800 & $31 / 4$ & $85 \cdot 0$ & $106 \cdot 3$ & & & & & \\
\hline 6 & $2000^{\mathrm{E}}$ & $33 / 2$ & $81 \cdot 0$ & $40 \cdot 5$ & & & & & \\
\hline \multicolumn{10}{|c|}{ Group 2: Before and after plasma infusion ( $90 \mathrm{~min}$ interval) } \\
\hline 7 & 1200 & $29 / 2$ & $53 \cdot 4$ & $47 \cdot 7$ & $66 \cdot 9$ & $15 \cdot 2$ & $-1 \cdot 7$ & $97 \cdot 5$ & $2 \cdot 5$ \\
\hline 8 & 1820 & $30 / 1$ & $53 \cdot 7$ & $29 \cdot 5$ & $71 \cdot 8$ & $16 \cdot \overline{8}$ & $+1 \cdot 3$ & $102 \cdot 6$ & $2 \cdot 6$ \\
\hline 9 & 780 & $26 / 1$ & $26 \cdot 6$ & $34 \cdot 1$ & $38 \cdot 5$ & $9 \cdot 8$ & $-2 \cdot 1$ & $108 \cdot 8$ & $8 \cdot 8$ \\
\hline 10 & 900 & $26 / 1$ & $43 \cdot 5$ & $48 \cdot 3$ & $53 \cdot 2$ & $7 \cdot 3$ & $+2 \cdot 4$ & $104 \cdot 7$ & $4 \cdot 7$ \\
\hline 11 & 1040 & $28 / 1$ & $42 \cdot 9$ & $41 \cdot 3$ & $55 \cdot \overline{2}$ & $8 \cdot 1$ & $+4 \cdot 2$ & $108 \cdot 2$ & $8 \cdot 2$ \\
\hline \multicolumn{10}{|c|}{ Group 3: Two measurements - no plasma given ( 30 min +190 min interval) } \\
\hline 12 & 1520 & $30 / 1$ & $68 \cdot 5$ & $45 \cdot 1$ & $57 \cdot 2$ & $-1 \cdot 8^{*}$ & $-9 \cdot 5$ & $85 \cdot 8$ & $14 \cdot 2 \dagger$ \\
\hline 13 & 1260 & $30 / 1$ & $42 \cdot 5$ & $33 \cdot 7$ & $36 \cdot 0$ & $-1 \cdot 8^{*}$ & $-4 \cdot 7$ & $87 \cdot 6$ & $12 \cdot 4 t$ \\
\hline 14 & 1100 & $28 / 1$ & $44 \cdot 4$ & $40 \cdot 3$ & $41 \cdot 3$ & $-1 \cdot 8^{*}$ & $-1 \cdot 3$ & $97 \cdot 2$ & $2 \cdot 8$ \\
\hline 15 & 1160 & $28 / 1$ & $26 \cdot 7$ & $23 \cdot 0$ & $22 \cdot 4$ & $-1 \cdot 8^{*}$ & $-2 \cdot 5$ & 89.6 & $10 \cdot 4$ \\
\hline 16 & 1740 & $33 / 1$ & 69.9 & $40 \cdot 2$ & $70 \cdot 2$ & $-1 \cdot 8^{*}$ & $+2 \cdot 1$ & 104.0 & $4 \cdot 0$ \\
\hline 17 & 2500 & $37 / 9$ & $148 \cdot 0$ & $59 \cdot 2$ & $141 \cdot 0$ & $-1 \cdot 8^{*}$ & $-5 \cdot 2$ & $97 \cdot 1$ & 2.9 \\
\hline 18 & 1300 & $28 / 1$ & $54 \cdot 8$ & $42 \cdot 2$ & $53 \cdot 2$ & $-1 \cdot 8^{*}$ & +0.2 & $100 \cdot 4$ & 0.4 \\
\hline
\end{tabular}

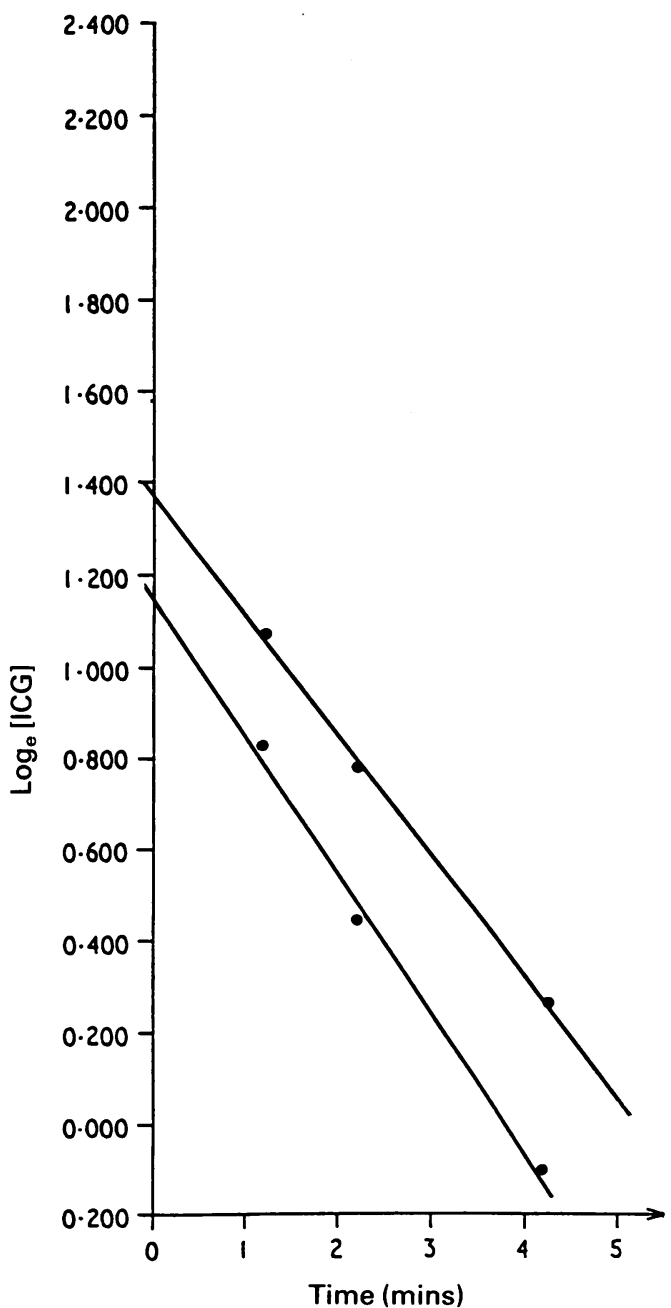

Figure 2 Decay curves from a patient. The top line refers to the preinfusion study and the bottom line to the study after the infusion of $15 \cdot 2 \mathrm{ml}$ of plasma.

the other extreme was grossly oedematous in established renal failure and was felt clinically to have a fluid overload. An exchange transfusion was undertaken in part to reduce the excessive fluid load.
The net volumes of plasma given to, or taken as samples from, the infants in groups 2 and 3 between the repeated volume measurements ranged from -1.8 to $15.2 \mathrm{ml}$. The plasma recovery ranged from $85 \cdot 8 \%$ to $108 \cdot 8 \%$, median $98 \cdot 9 \%$. The first two infants studied in group 3 had their second volume measurement made 30 minutes after the first, which resulted in the two lowest recovery values $(85 \cdot 8 \%$ and $87 \cdot 6 \%)$. By increasing the interval to 90 minutes the mean plasma recovery value for group 3 improved from $97 \cdot 66 \%$ to $98 \cdot 89 \%$.

No infant suffered any side effect from the study. One patient who was already in extremis from renal failure died eight days after the study. Two other infants died some weeks later from well recognised complications of extreme prematurity.

\section{Discussion}

This is the first report of the use of ICG for the measurement of plasma volume in ill neonates. The theory of the dye dilution technique for volume measurements is well documented in the literature. The main practical problem which has to be overcome in applying this dye dilution method to a small neonate is the volume of blood which must be taken from the infant for sampling the dye concentration at varying times and for constructing the ICG optical density standard curve, against which the subject's samples are compared.

To overcome these difficulties in this study the standard curves were prepared using pooled adult sera and all samples were diluted 1:1 with distilled water to reduce the volume of blood required from the infant at each samplng. We demonstrated that neat and diluted sera of both adults and infants had the same absorption spectrum, indicating that these two manoeuvres did not alter the assay results. In further studies we wish to show that differing concentrations of ICG in adult and infant sera behave similarly; we have no evidence to date to suggest that this is not so. 
The main source of error in the method arises from the limited number of blood samples that may be taken after ICG injection. We aimed to show that it was possible to make quite reasonable measurements of plasma volume using only three samples after injection to construct the decay curve. A minimum of three points is required to draw the straight line needed for extrapolation back to time zero to make allowance for dye lost from the intravascular space after the ICG injection. To produce an accurate decay plot the three points must be taken after the mixing time is complete, when the decline in dye log concentration falls at a constant rate. Although in adults the mixing time is recorded as 60 seconds, we cannot be certain that in all our infants that this was the case. It is possible that infants with large circulating volumes, or with poor cardiac output or organomegaly, may well have mixing times in excess of the reported 60 seconds in adults. The three points of the decay curve for the infant in renal failure (No 5) fell closely onto a straight line as did the points for the hydropic infant (No 6). No other infant had evidence of organomegaly or poor cardiac output. Initially we sampled at 1, 2, and 4 minutes after ICG injection. We found the scatter of the points on the decay curves improved for sampling times at $2,3 \cdot 5$, and 6 minutes, implying that the mixing time might be longer than 60 seconds. Sampling cannot be delayed for periods of up to 10 minutes, as used for Evans' blue in adults and infants, because ICG is rapidly removed from the circulation and the resulting concentrations would become unmeasurably small. However, our repeat measurements at 30 minutes compared with those at 90 minutes suggests that clearance in these infants is not as rapid as in an adult.

There is no 'gold standard' measurement of plasma volume in the neonate against which we can compare our results. The median plasma volume of $40.9 \mathrm{mg} / \mathrm{kg}$ compares favourably with the results of Linderkamp et al, who obtained $40 \cdot 4-54 \cdot 8 \mathrm{ml} / \mathrm{kg}$ using Evans' blue, ${ }^{5}$ and $37 \cdot 3$ $53.7 \mathrm{ml} / \mathrm{kg}$ using ${ }^{125} \mathrm{I}^{4}{ }^{4}$ Mollison, using Evans' blue in 46 term infants, found a range of $30.6-94.8 \mathrm{ml} / \mathrm{kg}$, median $43 \mathrm{ml} / \mathrm{kg}$. ${ }^{6}$ It also agrees well with published estimates of plasma volume derived from measurements of red cell volume, blood volume, and packed cell volume. Bentley and Lewis found a mean $41 \cdot 96 \pm 8 \cdot 86$ $\mathrm{ml}^{16}$; Jones et al found a mean of $38 \cdot 1 \pm 0.6 \mathrm{ml}$ for packed cell volume/red cell volume and $39.5 \pm 0.73 \mathrm{ml}$ for blood volume $/ \mathrm{red}$ cell volume. ${ }^{17}$ This agreement may suggest that the theoretical error of overestimating the plasma volume by albumin labels in sick, leaky patients is minimal and of the order inherent in any in vivo analysis.

The wide ranges found in volume measurements may be considered by some to be evidence of error in the method. The infants studied represented a considerable range of clinical conditions from a fluid overloaded infant in renal failure to a grossly fluid restricted postoperative infant, which would make it quite likely that their plasma volumes would not be within what might be considered a normal range. We believe the range found in our study was a true reflection of these infants' varying intravascular volumes.

We are about to install an $805 \mathrm{~nm}$ filter to a Cobas Mira (Roche). This micromethod will allow one third less blood to be taken at each sampling. It will mechanise the diluting and assays so that the speed and precision of the method will be enhanced. As smaller volumes are required it will then be possible to take a greater number of samples and so produce more points with which to construct the decay curves and so make the measurement more reliable. It will also be possible to take multiple samples immediately after the injection of ICG to study the mixing time.

This pilot study demonstrates the feasibility of performing repeated plasma volume measurements in the smallest and sickest of infants with the minimum of disturbance. Further refinements of the method are being undertaken to increase the precision and ease of application to routine clinical use.

We are grateful to the medical and nursing staff on the Peter Congdon Newborn Unit for cooperating with this study. MYA was supported by the Spastics Society.

1 Lawson HC. The volume of blood-a critical examination of methods for its measurement. In: Hamilton WF, Dow P, eds. Handbook of physiology. Vol 1 Washington DC: American Physiological Society, 1962:23-49.

2 Keith NM, Rowntree LG, Geraty JT. A method for determining the plasma and blood volume. Arch Int Med 1915;16:547-76

3 Gibson JG, Evans WA. Clinical studies of the blood volume: application of a method employing azo dye Evans' blue and spectrophotometer. $\mathcal{F}$ Clin Invest 1937;16:301-16.

4 Linderkamp O, Holthausen H, Seifert J, Butenandt I, Riegel $\mathrm{K}$. Accuracy of blood volume estimation in critically ill children using ${ }^{125} \mathrm{I}$-labelled albumin and ${ }^{51} \mathrm{Cr}$-labelled red cells. Eur $\mathcal{F}$ Pediatr 1977;125:143-51.

5 Linderkamp O, Mader T, Butenandt O, Riegel KP. Plasma volume estimation in severely ill infants and children using a simplified Evans' blue method. Eur $\mathcal{F}$ Pediatr 1977;125: $135-41$

6 Mollison PL, Veall N, Cutbush M. Red cell and plasma volume in newborn infants. Arch Dis Child 1950;25: 242-53.

7 Usher R, Shepard M, Lind J. The blood volume of the newborn infant and placental transfusion. Acta Paediatrica 1963;52:497-512.

8 Yao AC, Lind J, Tiisala R, Michelsson K. Placental transfusion in the premature infant with observation on transfusion in the premature infant with observation on
clinical course and outcome. Acta Paediatr Scand 1969;56: $561-6$.

9 Saigal S, O'Neill A, Surainder Y, Chua L-B, Usher R. Placental transfusion and hyperbilirubinaemia in the premature. Pediatrics 1972;49:406-19.

10 Bradley EC, Barr JW. Determination of blood volume using indocyanine green $\left(\right.$ Cardiac-Green $\left.{ }^{\circledR}\right)$. Life Sci 1968;7: $1001-7$

1 Busse MW, Zisowsky S, Henschen S, Panning B, Reilmann L. Determination of circulating blood volume by measurement of indocyanine green dye hemolysate: a preliminary study. Life Sci 1990;46:647-52.

12 Haneda K, Horiuchi T. A method for measurement of total circulating blood volume using indocyanine green. Tohuku $\mathcal{F}$ Exp Med 1986;148:49-56.

13 Parry BW, Bayly WM, Tarr B. Indocyanine green clearance and estimation of plasma volume in the normal horse. Equine Vet 7 1989;21:142-4

14 Mollison PL, Engelfriet CP, Contreras M. Blood transfusion in clinical medicine. Oxford: Blackwell Scientific, 1987.

15 Gathje J, Steuer RR, Nicholes RK. Stability studies on indocyanine green dye. F Appl Physiol 1970;29:181-5.

16 Bentley SA, Lewis SM. The relationship between total red cell volume, plasma volume and venous haematocrit. $B r \mathcal{F}$

17 Jones JG, Holland BM, Hudson IRB, Wardrop CAJ. Total circulating red cells versus haematocrit as the primary circulating red cells versus haematocrit as the primary
description of oxygen transport by the blood. $B r f$ description of oxygen tran 